REVISTA ANDALUZA DE ANTROPOLOGÍA.

NÚMERO 4: ENCRUCIJADAS PARA LAS SOCIEDADES PESQUERAS DEL SUR EN EL MARCO DE LA GLOBALIZACIÓN. MARZO DE 2013

ISSN 2174-6796

[pp. 165-172]

http://dx.doi.org/10.12795/RAA.2013.i04.09

\title{
GRAEBER, DAVID (2011). Debt: The First 5,000 Years. Brooklyn: Melville House, 534 pp. ${ }^{1}$
}

\section{Jordi A. López Lillo \\ Universitat d'Alacant}

Quizá se podría decir del planteamiento con el que se aborda el estudio de los grupos humanos, sus culturas, sus sociedadesysus historias, que pocoa poco va cambiando mucho. El último trabajo del estadounidense David Graeber se suma a este giro fundamental tan abierta y decididamente que casi pudiera pasar inadvertida su trascendencia, viniendo de un internacionalmente reconocido antropólogo contemporáneo. Sin duda, corren otros tiempos. En palabras del propio autor (p. 19) «for a very long time, the intellectual consensus has been that we can no longer ask Great Questions. Increasingly, it's looking like we have no other choice».

Concretamente, Debt se escribe desde la urgencia del escenario político y económico que inaugurara la crisis financiera de 2008, en el empeño de reconectar el discurso antropológico -las herramientas teóricas para la interpretación de los grupos humanoscon la forma en que comúnmente percibimos y explicamos desde nuestra propia cultura la realidad global, y en este sentido comienza a hacer justicia a las advertencias de Maurice Bloch (2005) sobre el objetivo social de la antropología. Digamos, con todas las licencias reduccionistas que conlleva una generalidad, que el de la London School of Economics acusaba la dejación de la antropología posmoderna a la hora de enfrentarse al fenómeno Homo sapiens desde una perspectiva holística, precipitando la consiguiente división actual de la percepción de la realidad entre: de un lado, la negación del acervo semiótico estructural en líneas interpretativas que replican más o menos acríticamente lo dicho con anterioridad a la «crítica contextual», es decir: durante la

1. Traducido también al castellano. Graeber, David (2012): En Deuda. Una historia alternativa de la economía. Barcelona: Ariel, 720 pp. 
primera mitad del siglo pasado; y del otro, la negación siquiera de la posibilidad de una salida estructural a dicha crítica a través de un juego de mecanismos aplicable a la totalidad de la diversidad cultural humana. Pues bien, por descontado, el esbozo histórico de la economía mundial que plantea Graeber, apoyado fundamentalmente en una abierta contestación del formalismo economicista, es una lanza rota a favor de una rearticulación teórica de la antropología contemporánea que pugne por corregir esta brecha epistemológica atenazante. Desde nuestro punto de vista, además, es una virtud añadida el hacerlo precisamente reactivando el análisis socio-cultural de la economía, usualmente encumbrada hasta la base mecánica de los sistemas humanos para aquel nutrido grupo de la primera negación, en un momento en que las autoridades estatistas se esfuerzan en la justificación tautológica -la economía por la realidad y la realidad por la economía-, mientras se incrementan los endeudamientos, los desahucios y los suicidios. Ésos sí: en la única realidad del todo indiscutible.

Sin embargo, tampoco puede escapar por obvio el hecho de que una revisión profunda de las dinámicas económicas humanas a lo largo de más de cinco mil años de devenir histórico es, sencillamente, inabarcable en una precisión determinante; o al menos inabarcable en una precisión determinante ocupando un solo volumen de quinientas páginas. Siendo de esta manera no puede sino levantar suspicacias lo que prácticamente acaba por resultar un aire de monumentalismo estadounidense, entre sencillos argumentos rotundos y compases de relojero, aparentemente carente de inconclusiones, puntos ciegos o excepciones. Es por esto que, centrándose únicamente en una macrovariable -la economía, y más específicamente la deuda- la causalidad histórica queda harto difuminada, al punto de que en ocasiones la secuenciación de Graeber no se explica, sino que queda casi al azar de una onda hertziana más o menos autista en la cual se entrampan las idas y venidas de la humanidad.

Y no solo eso, sino que la naturalización del recurso a la paradoja acaba por subvertirse al punto del paroxismo, del fin en sí mismo, en lo que, siguiendo a la antropóloga bonaerense Dulcinea Tomás, venimos calificando de «Shock Hermeneutics». De esta manera, si más de una vez el texto se vuelve acertadamente -por lo que toca a la libre irreverencia del rechazo a las explicaciones lineales, prefabricadas y maniqueas hasta la incontestabilidad, tan extendidas en el actual imaginario político de la «izquierda de posiciones» europea (sensu Tamzali, 2010)- incluso contra los cánones del discurso hegemónico en lo contrahegemónico, con ejemplos como el de la reclusión femenina del patriarcado como un mecanismo de protección familiar (p. 179) o el racismo ideológico como un dispositivo que salvaguardara la oposición ética a esclavizar seres humanos equivalentes (p. 212), esta deriva de la paradoja alcanza la cota del grotesco cuando, por citar quizá el caso más evidente, vacía el concepto de medievo para rellenarlo como una categoría esencialmente extraeuropea (pp. 251 y ss.). No cabe duda de que una panorámica planetaria no puede 
sino arrinconar en su intención las periodizaciones etnocéntricas y tratar de categorizar el continuum de lo real en un tono que forzosamente ha de desdibujar algunos límites preasumidos culturalmente; a nuestro modo de ver, empero, el efecto correlativo de «percepción sesgada» o «torcida» no se debe tanto a un fallo en la valoración de las categorías originales como, precisamente, a su reordenación. Es decir: si usualmente se percibe en nuestra cultura la Edad Media de una manera muy diferente a la que plantea Graeber no es porque «we're used to thinking of the Middle Ages as something that happened primarily in Western Europe» y esto sea erróneo -lo que es incoherente por la sencilla razón de que es una categoría endógena, diseñada por y para ese contexto tópico y cultural-, sino porque nuestro autor decidió etiquetar su nueva categoría mundial justamente con el mismo epíteto familiar, y quebrar nuestro significado. Sin duda en lo anterior subyace una intencionalidad clara. Haberlo explicado de esta manera habría resultado más correcto, pero menos efectista.

En cualquier caso Debt contiene reflexiones tan interesantes como necesarias, y esto merece que sobrevolemos con más detenimiento algunos contenidos del libro.

A través de doce capítulos agrupables en dos grandes bloques, Graeber se encarga, primero, de analizar en profundidad los apriorismos de la llamada «ciencia» económica que se construyera sobre la base de la Escuela clásica de Smith y Ricardo para, habiéndola puesto en jaque según una línea argumental que no puede evitar las semejanzas con la trazada por los substantivistas de Polanyi (2003) o los posteriores ensayos sobre la metaforización económica de Gudeman (1986) -aun en ausencia de una auto-vinculación explícita-, plantear su propuesta a propósito de la construcción simbólica de la «práctica» relacional económica, posiblemente la pieza positiva más novedosa de la obra. En un segundo bloque abordado sin solución de continuidad, se presenta una periodización histórica según el tratamiento cultural de la deuda desde el inicio del registro escrito -valga señalar que a lo largo de Debt se estudia la casuística de grupos ágrafos, pero el tipo de fuentes etnográficas que lo sustentan las alejan de la estricta secuenciación cronológica- hasta lo que el mundo anglosajón comienza a denominar la Gran Recesión y Graeber, significativamente, «The Beginning of Something Yet to Be Determined».

En grandes trazos, el argumento parte de la idea de que la deuda no es únicamente una categoría económica sino también moral, definiéndola preliminarmente como una obligación que puede ser cuantificada con precisión. El problema de esa cuantificación precisa es la puerta que abre a la operatividad impersonal y ésta, a su vez, a la justificación cultural de situaciones que contextualizadas serían socialmente injustificables, como por ejemplo expulsar forzosamente de su hogar a una familia que se ha visto privada de recursos suficientes como para hacer frente a su mantenimiento; es decir: mientras la obligación retiene una naturaleza funcional primariamente contextual y difusa, la deuda establecida a través del cálculo economicista permite la inversión de tal tendencia sin 
abandonar decididamente la construcción cultural de la moralidad. La herramienta del dinero -tradicionalmente conceptuado en la tríada de medio de cambio, unidad de cuenta y reserva de valor- nos aparece aquí como un medio de cálculo sofisticado, pero si la explicación clasicista para su aparición lo hace evolucionar desde el trueque directo, lo cierto es que la antropología no ha encontrado sociedad alguna que practique lo que Graeber (pp. 23 y ss.) llega a calificar de esquematización fantasiosa e irreal planteada por Smith y repetida hasta la actualidad en todos los tratados de economía al uso. Esto nos aboca a una de las ideas-fuerza más determinantes del libro, perceptible meciendo recurrentemente los esquemas de piezas argumentales enteras y, sin embargo, infraexplotada por el autor, a nuestro modo de ver, en toda su potencialidad sistémica: no ocurre que las sociedades del registro etnográfico desconocieran el mecanismo del trueque, sino que no lo utilizaban como método de integración interno; de hecho estos grupos, por lo común cohesionados en diferentes sistemas de obligaciones, practicaban efectivamente el trueque con extranjeros, desconocidos o, en definitiva, enemigos potenciales. Si enlazamos esto con el hecho de que en tales grupos los límites de la sociedad encajan perfectamente con los de la comunidad tönniesiana, podríamos decir, sencillamente, que el trueque era un mecanismo extracomunitario.

Tal asunción nos sitúa ante un escenario con mayores visos de probabilidad histórica, en el cual el crédito antecedería en mucho a la moneda como expresión del dinero. Con ello, Graeber se alinea con el injustificadamente ignorado Mitchell-Innes y los autores posteriores englobados bajo la etiqueta de Primordial-debt Theorists: «the core argument is that any attempt to separate monetary policy from social policy is ultimately wrong [...]. Governments use taxes to create money, and they are able to do so because they have become the guardians of the debt that all citizens have to one another. This debt is the essence of society itself» (p. 56). Una vez añadimos al engranaje la sobradamente demostrada relación de dependencia entre la existencia de mercados y del Estado, otro anatema del imaginario liberal, podemos concluir el cuadro que esbozábamos líneas arriba achacando el desarrollo de este paquete de mecanismos económicos -deuda, dinero, mercado, etc.- al surgimiento de sociedades no-comunitarias, a la heterogeneidad que formulara Redfield (1973). Retengamos esta idea.

En cualquier caso, a lo acertado de la secuencia racional presentada por Graeber al respecto, se suma la coherencia con una «naturaleza» del humano antes como un animal semiótico, que crea y vive inserto en tramas simbólicas, que como el clasicista Homo ceconomicus (p. 58). Es siguiendo esta línea que el autor explorará algunas de las principales tradiciones filosóficas, desde los Vedas a los Biblia mediterráneos, para subrayar la convergencia en la percepción de la deuda como un elemento seminal de la vida, expresado en las obligaciones individuales para con los antepasados y la comunidad inmediata en primer término, y el universo en su totalidad en último. Lo interesante de 
traer a colación la explicación filosófica es, precisamente, que a pesar del léxico empleado, el propio desarrollo semántico acaba por desmarcarlo del concepto economicista que definiéramos. Al evidenciar la imposibilidad de saldarla en tales términos -por lo pronto, a causa de la continencia elemental de las partes, el individuo y el universo, por la cual resolviera Nietzsche que el dios cristiano pagase consigo mismo la deuda de la humanidad- se apunta, nuevamente, a una interpretación bajo la categoría de obligación con el fin de apelar al mero reconocimiento de su existencia por los canales socio-culturales convenidos -por lo tanto, mediante explicitaciones cultuales, pseudo-pagos no relativos o una sujeción moral que en última instancia se verifica en el respeto a la comunidad y su ley-. Esta lógica choca con la presunción de contabilidad natural clasicista, pero es congruente con lo registrado por la etnografía para sociedades comunitarias, donde el rechazo al cómputo preciso de las obligaciones sociales es explícito (p. 79). Así, opinamos que Graeber pinza una nervadura fundamental de la problemática al apuntar que aquella obligación se vuelve deuda y bascula hacia la tragedia de la mano de la violencia y las dinámicas estatistas: cuando un segmento social se apodera de la autoridad y, legitimado para gestionar la deuda, gestiona además la violencia.

Llegados a este punto, nuestro autor plantea una digresión básica. Al contrario del acento en la producción usual en el formalismo abrazado desde el economicismo liberal hasta las distintas variantes marxianas, de la contra-propuesta que desarrollaran los substantivistas centrada en los sistemas de integración, e incluso de incipientes modelos que apuntan a una centralidad del consumo en el análisis de la ordenación económica (cf. Narotzky, 2004), Graeber plantea un esquema triádico sustentándose en la mediación moral de las relaciones económicas. Con ello rescata de una tacada el término que acuñó Scott (1976) y su polémica corolaria, haciéndonos necesario aclarar de nuevo aquí que lo que se dirimía y dirime no es la bondad militante de las prácticas no capitalistas sino la construcción cultural de cualquier práctica económica y el juego de expectativas y costumbres que rigen sus lógicas; en esencia, algo ya abordado sistémicamente por autores como Geertz (1978) y, sobre todo, Bourdieu (2003), eso sí: con menos revuelo. Sea como fuere, lo cierto es que Graeber aborda la cuestión desde una perspectiva novedosa.

Empezando por librarlo de lo que calificará de «comunismo mítico» o «épico», su principio de comunismo parte del rechazo analítico a unos cimientos basados en la propiedad, para conceptuarlo operacionalmente según la clásica máxima «de cada cual según sus capacidades, a cada cual según sus necesidades» leída en clave kropotkiniana. Este «Baseline Communism» sería prácticamente intercambiable por la «reciprocidad generalizada» de Sahlins (1983) en tanto que basado en la idea de eternidad y por ello rehusando asimismo la contabilidad, si bien tiene la ventaja sobre éste de romper abiertamente el marco que estableciera Polanyi y, con ello, verse más libre de la secuenciación evolucionista para afirmar que el comunismo siempre es un principio rector 
básico de toda sociedad, infiltrándose desde en determinadas relaciones comunitarias de parentesco y amistad hasta en el eventual retro-ajuste de la propia situación de mercado (p. 102). El segundo principio operacional sería el del intercambio, marcado por una impersonalidad que siguiendo el hilo argumental de Debt podríamos complementar con la idea de descontextualización de las partes. Tal pérdida de referentes sociales precisos permite, precisamente, una precisión en los intercambios que sin embargo sí lleva aparejada un tipo exacto de relación mutua: la percepción de cierta equivalencia, si más no reificada ad hoc durante la transacción pues nótese que se parte de la idea de ausencia de relaciones sociales continuadas, como en el trueque extra-comunitario. Las partes de un intercambio se presentan como iguales y, finalizada la transacción, marchan como iguales poniendo fin a su relación; es por ello que en determinados sistemas de integración, quebrado o en ausencia del sentimiento comunista, el desequilibrio en las transacciones -la deuda- habilita moralmente la cohesión social en la línea del clásico don y contra-don de Mauss. Finalmente, Graeber intitula su tercer principio jerarquía, el cual, definido a través de la «lógica del precedente» y de la delimitación manifiesta y aceptación consuetudinaria de las líneas sociales de superioridad-inferioridad, pone nuevamente en juego la construcción de la identidad operacional como un factor cardinal en la práctica económica. Sin embargo, nuestro autor se apresura a añadir una excepción sinecdótica a estos dos polos definitorios en la dinámica de la «redistribución jerárquica», esta vez sí, como sistema de integración. Así, en determinados grupos el establecimiento de un precedente comportamental y una demarcación de las relaciones jerárquicas vinculados a la redistribución no resulta en una tendencia a la desventaja material para los «inferiores» sino para los «superiores», y esto sucede, según Graeber -y no podemos sino celebrar la perspicacia-, en tanto que en dichos casos la aristocracia no está ni legitimada ni capacitada para ejercer un poder coercitivo, es decir: donde no ha habido una segregación de la gestión de la violencia; este fenómeno entroncaría con la explicación de los procesos de eufemización de la reciprocidad allí donde la fractura social sí se ha osificado.

Si esta clasificación no responde a «tipos» de sociedades sino de disposiciones morales que rigen, mediante diferentes combinaciones y determinaciones, el comportamiento relacional económico en cualquier tipo de sociedad, de lo que se encarga Debt a partir de este punto es de las transiciones y sus formas. Con este fin retomará el hilo argumental donde lo dejó, en el dinero, para reconstruir la historia económica a partir estrictamente de las evidencias antropológicas e históricas, esto es: para abordar la conceptuación del llamado dinero primitivo. En este sentido, opinamos, el libro adolece de la ausencia de una revisión exhaustiva de la literatura anterior y un establecimiento de relaciones sistémicas -donde y con quien fuera posible- entre aquellos modelos y las categorías diseñadas por Graeber; esto habría, por ejemplo, clarificado por qué el dinero primitivo no se aplica a todas las esferas económicas extrapoladas desde la enunciación africana 
de los Bohannan (pp. 145 y ss.) o, sobre todo y más adelante, coadyuvado a distinguir netamente entre «mercados» y «sistema mercantil autorregulado», en los términos que fijara Polanyi, cuando el devenir histórico complejice el panorama esbozado por Graeber (p. 260). Esto viene a sumarse a una obliteración constante de factores que a nuestro parecer devienen absolutamente fundamentales en la explicación de algunos de los procesos que el estadounidense circunscribe a movimientos espasmódicos en la percepción de la deuda, como es el caso de la citada situación de homogeneidadheterogeneidad redfieldiana o, en general, los procesos de integración y desintegración que se verifican en distintos contextos históricos y, sencillamente, no se pueden obviar ni tan siquiera apelando a la universalidad humana, pues en tal marco el riesgo no es de imprecisión sino de irrealidad.

Ha sido ante tal tesitura que nos ha parecido más oportuno centrar nuestro comentario antes en la formulación teórica que en una aplicación planetaria lamentablemente poco contextualizada. Ahora bien, sin duda mucho más habrá que lamentar de no comenzar a repensar profundamente la economía en los términos que Graeber ensaya, librada del dogmatismo disciplinar formalista, inserta en las tramas culturales que definen y permiten la sociedad; sujeta a nuestra construcción, y no a la inversa. Esta otra intencionalidad es lo que sin duda convierte Debt en una lectura fundamental para un debate fundamental. 


\section{REFERENCIAS BIBLIOGRÁFICAS}

Bloch, Maurice (2005) «Where did anthropology go? Or the need for "human nature"», en Essays on cultural transmission. Oxford: Berg.

Bourdieu, Pierre (2003) Las estructuras sociales de la economía. Barcelona: Anagrama.

Geertz, Clifford (1978): «The Bazaar Economy: Information and search in peasant marketing». The American Economic Review, vol. 68, n. 2, pp. 28-32.

Gudeman, Stephen (1986) Economics as culture: Models and metaphors of livelihood. Londres: Routledge y Kegan Paul.

Narotzky, Susana (2004) Antropología económica: Nuevas tendencias. Barcelona: Melusina.

Polanyi, Karl (2003 [1944]) La gran transformación: Los orígenes políticos y económicos de nuestro tiempo. México: Fondo de Cultura Económica.

Redfield, Robert (1973 [1953]) El mundo primitivo y sus transformaciones. México: Fondo de Cultura Económica.

Sahlins, Marshall (1983 [1974]) Economía de la Edad de Piedra. Madrid: Akal.

Scott, James C. (1976) The moral economy of the peasant: Rebellion and subsistence in southeast Asia. New Haven: Yale University Press.

Tamzali, Wassyla (2010) El burka como excusa: Terrorismo intelectual, religioso y moral contra la libertad de las mujeres. Barcelona: Saga Editorial. 